\title{
Some aspects of double twinning in hexagonal metals
}

\section{A. Ostapovets}

\author{
Central European Institute of Technology-Institute of Physics of Materials (CEITEC IPM), \\ Academy of Sciences of the Czech Republic, Žižkova 22, CZ-616 62 Brno, Czech Republic \\ E-mail: ostapov@ipm.cz
}

\section{Paidar}

\author{
Institute of Physics, Academy of Sciences of the Czech Republic, Na Slovance 2, CZ-182 21 Prague 8, Czech Republic
} E-mail: paidar@fzu.cz

Received April 18, 2018, published online July 26, 2018

\begin{abstract}
When plastic deformation cannot be carried by dislocations, mechanical twinning is often activated. This situation often takes place in hexagonal materials. In addition to general grain boundaries, twin boundaries as special interfaces play an important role not only for mechanical properties but for other properties of materials as well. This short paper is focused only on some processes related to double twinning and the conditions of its occurrence are considered. Geometrical aspects are analyzed for development mechanisms of different twin interfaces in connection to double twinning.
\end{abstract}

Keywords: hexagonal metals, mechanical properties, twinning.

\section{Introduction}

Deformation twinning can be encountered in various metals with hexagonal close packed (hcp) structure such as magnesium, cobalt, titanium and their alloys [1]. Twinning makes significant contribution to plastic deformation of magnesium and accommodates the deformation along the $\langle c\rangle$ axis in hcp metals in general ( $a$ and $c$ denote the parameters of hcp lattice). Twinning is activated due to relative hardness of non-basal slip, for instance, in magnesium $[2,3]$. There are several twinning modes observed, however, the most frequent one is so-called "tension/extension" twinning on the twinning plane $(10 \overline{1} 2)$ with the twinning direction $[10 \overline{1} 1]$.

A large effort has been paid to understand deformation twinning in the past, however, some aspects of its mechanism still remain unclear. For example, the presence of basal-prismatic (BP) interfaces that border the twin in the matrix. As a consequence, the twin boundaries can consist of the symmetrical $(10 \overline{1} 2)$ and non-symmetrical (0001)/ $(10 \overline{10})$ facets, the later represent a termination of one grain by the basal plane and on the other side by the prismatic plane. These facets represent abrupt changes in the orientation of the interface. The BP interfaces have low formation energies that are comparable to the energy of a twin boundary [4-6] and therefore, it is expected that their occurrence can affect the kinetics of twin boundary migration.
Similarly to activation of secondary dislocations with a smaller Schmid factor, a double twinning is observed, it means that a new twin can appear inside of the already existing twin. The new twins can be of different type, for example, the combination of the (10 $\overline{1} 2)$ and $(10 \overline{1} 1)$ twins, but the both twins can be of the same type as in [7].

Although the mechanical behavior of twinned metals has been intensely investigated [8,9], scientific and technological challenges remain. The influence of defective twin boundaries on deformation mechanisms and plasticity are not yet fully understood. An in-depth understanding of the mechanisms of deformation twinning in hep materials, such as nucleation, propagation/growth, dislocation-twin, and twin-twin interactions, is essential for more extensive application of these materials. A great attention is also paid in the last years to nanotwinned structures. Moreover, twinning plays also a fundamental role in shape memory materials, it is a basic part of structural phase transformations [10].

\section{Double twinning}

Let us compare first the $\{10 \overline{1} 2\}\langle\overline{1} 011\rangle$ and $\{10 \overline{1} 1\}\langle\overline{1} 012\rangle$ twins where the first symbol denotes the twin boundary (TB) plane and the second the twinning direction (TD). For the ideal $c / a$ ratio of $4 / \sqrt{6}=1.633$, the periods for the twin boundary atomic structure in twinning direction are about $2.38 a$ and $3.70 a$, respectively. The misorientation angles between the matrix and the twin are $86.6^{\circ}$ and $55.9^{\circ}$, re- 
spectively. Those are the angles of rotation about the $\langle 1 \overline{2} 10\rangle$ direction between the matrix and the twin. The angles between the $\langle c\rangle$ axis and the TD are about $46.7^{\circ}$ and $27.9^{\circ}$, respectively. The angles between the $\langle c\rangle$ axis and the normal to $\mathrm{TB}$ are about $43.3^{\circ}$ and $62.1^{\circ}$, respectively. Then the Schmid factors for loading along the $\langle c\rangle$ axis for the twinning are about 0.499 and 0.414 , respectively. The Schmid factors for the glide of $\langle a\rangle$ dislocations on the basal plane in the matrix are zero since the basal plane is perpendicular to the $\langle c\rangle$ axis and also all three $\langle a\rangle$ directions are perpendicular to it.

However, the geometry inside the secondary $\{10 \overline{1} 2\}$ or $\{10 \overline{1} 1\}$ twin is different. We consider only the secondary twin variants with the same rotation $\langle a\rangle$ axis that remains perpendicular to the $\langle c\rangle$ axis. However, the other two $\langle a\rangle$ directions are inclined to it about $54^{\circ}$ and $40^{\circ}$, respectively. The normal to the basal plane are now about $86.6^{\circ}$ and $55.9^{\circ}$ from the matrix $\langle c\rangle$ axis, respectively. Then the Schmid factors for the basal slip inside the secondary twin are 0.035 and 0.429 , respectively. It clearly indicates that the basal slip inside the $\{10 \overline{1} 2\}\langle\overline{10} 011\rangle$ secondary twin is almost impossible to be activated while it can occur inside the $\{10 \overline{1} 1\}\langle\overline{1} 012\rangle$ secondary twin.

The angle between the matrix $\langle c\rangle$ axis and TD inside the secondary $\{10 \overline{1} 2\}\langle\overline{10} 11\rangle$ twin of the same type is $39.9^{\circ}$ and the angle between the matrix $\langle c\rangle$ axis and the normal to TB of the secondary twin is $50.1^{\circ}$, and hence the Schmid factor for the nucleation of the secondary twin is 0.492, almost as high as the Schmid factor 0.499 for the nucleation of the primary twin. However, the preferential sense of loading is different for the growth of primary and secondary twins. This fact can lead to a conclusion that double extension twinning should be a rare phenomenon. In practice, the double twinning is quite frequent in the cases when a complex multi-axes loading is applied, for instance, double twins are easily nucleated during rolling or extrusion $[7,11]$. It is worth noting that Schmid factor for the nucleation of the secondary twin is the same also for the loading along the $\langle 10 \overline{1} 0\rangle$ axis, which is perpendicular to the $\langle c\rangle$ axis. Co-existence of stress components along the $\langle c\rangle$ and $\langle 10 \overline{1} 0\rangle$ axes can be easily reached during processes of material forming.

The angle between the matrix $\langle c\rangle$ axis and TD inside the secondary $\{10 \overline{1} 1\}\langle\overline{1} 012\rangle$ twin of the same type is only $6.2^{\circ}$ and the angle between the matrix $\langle c\rangle$ axis and the normal to TB of the secondary twin is $83.8^{\circ}$, and hence the Schmid factor for the nucleation of this secondary twin is only 0.107 , much smaller than the Schmid factor 0.429 for the activation of the basal slip.

As another possibility let us consider the nucleation of the $\{10 \overline{1} 1\}\langle\overline{10} 12\rangle$ twin inside the primary $\{10 \overline{1} 2\}\langle\overline{1} 011\rangle$ twin. The angle between the matrix $\langle c\rangle$ axis and TD inside the secondary $\{10 \overline{1} 1\}\langle\overline{1} 012\rangle$ twin is only $9.6^{\circ}$ and the angle between the matrix $\langle c\rangle$ axis and the normal to TB of the secondary twin is $80.4^{\circ}$, and hence the Schmid factor for the nucleation of the $\{10 \overline{1} 1\}\langle\overline{1} 012\rangle$ secondary twin is only 0.164 , much smaller than the Schmid factor 0.492 for the nucleation of the $\{10 \overline{1} 2\}\langle\overline{1} 011\rangle$ secondary twin.

It can be concluded that from the point of view of the Schmid factor the nucleation of the secondary twin $\{10 \overline{1} 2\}$ $\langle\overline{10} 011\rangle$ of the same type as the primary twin is more likely contrary to the nucleation of the $\{10 \overline{1} 1\}\langle\overline{1} 012\rangle$ secondary twin.

\section{Twin-twin interfaces}

Let us consider the interfaces, which can be nucleated between the double twinned region and the matrix. We again limit our considerations to the case when the primary and secondary twins have a common $\langle a\rangle$ axis. In principle, the matrix-double twin interface is analogous to the twintwin interface. Indeed, if one considers the primary twin as matrix, the initial matrix and the secondary twin can be interpreted as two twin variants obtained from the matrix.

The result of twin interaction can be considered from different viewpoints. The strain compatibility can be analyzed on macroscopic level and the interaction of interfacial defects can be studied on microscopic level. Let us consider the interacting conjugate $(10 \overline{12})$ and $(10 \overline{12})$ twins. It can be proven $[12,13]$ that shape strains produced by twinning shear of these two variants are the same. They correspond to the elongation along the [0001] direction and contraction along the $[10 \overline{1} 0]$ direction. The difference between the twin variants is a small rotation, the misorientation between them is only about $7^{\circ}$ about the $\langle a\rangle$ axis. Consequently, the strain compatibility can be always easily reached. The classical theory of deformation twinning claims that the twin interface can lie along plane, which is invariant to deformation. However, this idea is not fruitful for prediction of a possible twin-twin boundary in the considered case. Any plane can satisfy strain compatibility condition in this case. However, the experiment and computer modelling [14] demonstrate that there some preferable interfaces exist. The basal-basal and prismatic-prismatic boundaries are often reported in the contact regions of two twins. Such interfaces can be also recognized as stacking faults.

A dichromatic complex for the (10 $\overline{1} 2)$ twin boundary is shown in Fig. 1(a). The complex is obtained by superposition of atomic positions for the parent and twin crystals. The black symbols correspond to the parent crystal and the white symbols correspond to the twin crystal. The atomic positions are projected in the [1 $\overline{2} 10]$ direction. The arrows, which connect the black and white atoms, correspond to possible Burgers vectors of the twinning dislocations. Such dislocations produce steps on the twin boundary as it is shown in Fig. 1(b). Step-like interfacial dislocations are called disconnections. Migration of disconnections along the boundary leads either to the twin growth or to dissolution depending on direction of migration. The $b_{2 / 2}$ disconnection has the step height equal to two $\{10 \overline{1} 2\}$ interplanar distances in the black as well as in the white lattice. This 


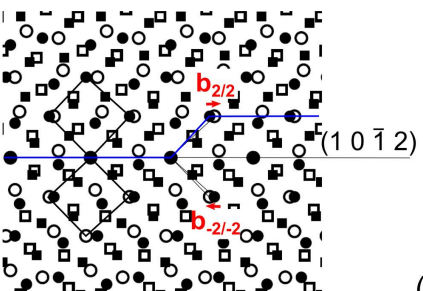

(b)

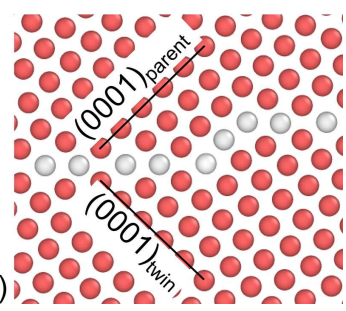

Fig. 1. (Color online) (a) Dichromatic complex for (10 $\overline{1} 2)$ twin boundary. Projection in the [1 $\overline{2} 10]$ direction. Rectangles show the projections of hexagonal unit cells. Possible Burgers vectors of $\mathbf{b}_{2 / 2}$ disconnections are marked by the arrows. (b) The $\mathbf{b}_{2 / 2}$ disconnection produces a step on the twin boundary. This image was obtained by atomistic simulations.

fact is marked by the $2 / 2$ subscript. In the case of $\{10 \overline{1} 2\}$ twin, the migration of $\mathbf{b}_{2 / 2}$ disconnections produces a correct value of twinning shear.

A consequence of the disconnection mechanism of the twin growth is that two twins interact through the interfacial steps. It can be concluded from the dichromatic complex in Fig. 1(a) that a disconnection step can lie along the basal plane in one crystal and along the prismatic plane in the other one. The disconnection Burgers vector can put these two planes into coalescence. It is demonstrated in Fig. 1(b) that the relaxed disconnection core contains inside a basal-prismatic microfacet. These cores were obtained by computer simulations using EAM interatomic potential of Liu et al. [15]. Details of a real structure of disconnection step may depend on the acting interatomic forces. The occurrence of basal-basal and prismatic-prismatic interfaces can be understood as a consequence of interaction between the basal-prismatic interfaces of different twins.

The basal-prismatic interfaces are observed not only in the cores of disconnections. Long basal-prismatic facets can be formed in the twin tips. It was shown that such facets can be also formed by a pile-up of disconnections gliding in the parallel planes [16].

The twin-twin interaction obtained by computer simulation is shown in Fig. 2. The basal-basal boundary is formed in the contact region of two twins. This boundary can be interpreted as a standard I1 stacking fault. It is worth noting that the I1 fault terminates in the twin boundaries. Due to this fact a Frank partial is not necessar-

(a)
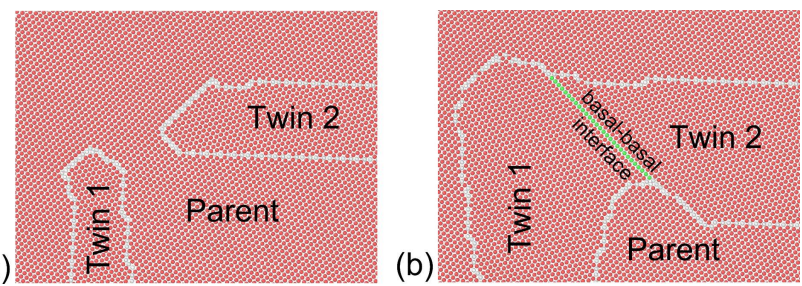

Fig. 2. Interaction of two $\{10 \overline{1} 2\}$ twins. (a) Initial state of interacting twin tips. (b) Basal-basal interface formed after interaction. ily present in the termination place in contrast to the case when the I1 fault terminates inside the bulk crystal. As a consequence, the growth of such a stacking fault does not need point defects participation.

\section{Discussion}

The $c / a$ ratio of magnesium 1.624 is only about $0.6 \%$ smaller than the ideal value of $4 / \sqrt{6}=1.633$. On the other hand the $c / a$ ratio of zinc 1.865 is about $14.2 \%$ higher than the ideal value, it is even about $7.7 \%$ higher that $\sqrt{3}$.

Nevertheless, the misorientation angle between the $\{10 \overline{1} 2\}$ twin and matrix for zinc is about $94.2^{\circ}$ and hence the angle measured between the equivalent crystallographic planes is about $85.8^{\circ}$ what is practically the same angle as for magnesium $86.6^{\circ}$.

Formation of the compressive/contraction $\{10 \overline{1} 1\}$ twins due to a strain parallel to the $\langle c\rangle$ axis and following nucleation of secondary extension $\{10 \overline{1} 2\}$ twins inside the primary twins is discussed in [17]. Moreover, in magnesium alloy AZ80 deformed at nitrogen temperature, a double twinning $\{10 \overline{1} 2\} /\{10 \overline{1} 2\}$ were reported in [17]. This type of double twinning were also observed experimentally in $[7,18,19]$. In principle it may occur also in cobalt with only slightly different $c / a$ ratio of 1.623 and recently, we have found it in zinc with completely different $c / a$ ratio of 1.856 [20].

Since the $c / a$ ratio of magnesium is smaller than $\sqrt{3}$, the $\{10 \overline{1} 2\}$ twinning causes extension in the $\langle c\rangle$ direction but the $\{10 \overline{1} 2\}$ twins were observed also for the external compression along the $\langle c\rangle$ direction [21]. When the basal slip is not activated, the $\{10 \overline{1} 2\}$ twinning has the second lowest critical resolved shear stress (CRSS) next to the basal slip [22] contrary to the $\{10 \overline{1} 1\}$ twinning. According to [23], CRSS is $23 \mathrm{MPa}$ for basal $\langle a\rangle$ slip, $95 \mathrm{MPa}$ for prismatic $\langle a\rangle$ slip, $111 \mathrm{MPa}$ for pyramidal $\langle c+a\rangle$ slip and $67 \mathrm{MPa}$ for $\{10 \overline{12}\}$ twinning. Nevertheless, according to [24], CRSS for the $\{10 \overline{1} 1\}$ twinning is much larger than that for the $\{10 \overline{1} 2\}$ twinning.

Considering only Schmid factors the activation of two conjugate twins $\{10 \overline{1} 2\}$ and $\{10 \overline{12}\}$ for the straining along the $\langle c\rangle$ axis can occur with the same probability. Notice that the Schmid factor takes into account only the normal to the slip/twinnig plane and the direction of slip/twinning without its sense (plus or minus sign). The slip of dislocations is usually the same in both directions and twinning can be different. Nevertheless, this type of twin polarization has not been discussed here. When two twins with the $\langle 1 \overline{2} 10\rangle$ identical rotation axis interact and the misorientation between them is only about $7^{\circ}$ the arising interfaces behave as a low-angle grain boundary with special plane inclinations close to the basal and prismatic planes as demonstrated in our computer simulations. Such interfaces were observed by high-resolution electron microscopy in $[14,25]$ and it was found that the plane of that interface is close to the $\{10 \overline{1} 0\}$ prismatic or $\{0001\}$ basal plane. 


\section{Conclusions}

A two scale research reported in this paper is helpful to improve our understanding of complex processes of twinning. A combination of the macroscopic (Schmid factor analysis) and atomistic (computer modelling) approaches shows under which conditions double-twinning in hexagonal metals can occur and which types of interfaces can be encountered.

It was shown that double-twinning nucleation can easily arise in hexagonal materials. Atomic simulations demonstrate that interaction of twins can lead to formation of special interfaces of stacking fault types. It can be anticipated that formation of such interfaces is not a serious obstacle for further twin growth and plastic deformation.

\section{Acknowledgments}

The authors gratefully acknowledge the financial support of the Czech Science Foundation (Project No. 1614599S).

1. J.W. Christian and S. Mahajan, Prog. Mater. Sci. 39, 1 (1995).

2. W.B. Hutchinson and M.R. Barnett, Scripta Mater. 63, 737 (2010).

3. A. Chapius and J.H. Driver, Acta Mater. 59, 1986 (2011).

4. J. Wang, L. Liu, C.N. Tome, S.X. Mao, and S.K. Gong, Mater. Res. Lett. 1, 81 (2013).

5. B. Xu, L. Capolungo, and D. Rodney, Scripta Mater. 68, 901 (2013).

6. M. Ghazisaeidi and W.A. Curtin, Modell. Simul. Mater. Sci. Eng. 21, 055007 (2013).

7. A. Jäger, A. Ostapovets, P. Molnár, and P. Lejček, Philos. Mag. Lett. 91, 537 (2011).

8. I.J. Beyerlein, X. Zhang, and A. Misra, Ann. Rev. Mater. Res. 44, 329 (2014).

9. J. Wang and X. Zhang, MRS Bulletin 41, 274 (2016).

10. R. Mirzaeifar, K. Gall, T. Zhu, A. Yavari, and R. DesRoches, J. Appl. Phys. 115, 194307 (2014).

11. A. Ostapovets, J. Bursik, K. Krahula, L. Kral, and A. Serra, Philos. Mag. 97, 1088 (2017).

12. A. Ostapovets and P. Molnar, Scripta Mater. 69, 287 (2013).

13. A. Ostapovets, J. Bursik, and R. Groger, Philos. Mag. 95, 4106 (2015).

14. Q. Sun, A. Ostapovets, X. Zhang, L. Tan, and Q. Liu, Philos. Mag. 98, 741 (2018).

15. X.Y. Liu, J.B. Adams, F. Ercolessi, and J.A. Moriarty, Modell. Simul. Mater. Sci. Eng. 4, 293 (1996).

16. A. Ostapovets and R. Gröger, Modelling Simul. Mater. Sci. Eng. 22, 025015 (2014).

17. J. Jain, J. Zou, C.W. Sinclair, and W.J. Poole, J. Microscopy 242, 26 (2011).

18. P. Cizek and M.R. Barnett, Scripta Mater. 59, 959 (2008).

19. D. Ando, J. Koike, and Y. Sutou, Acta Mater. 58, 4316 (2010).
20. J. Čapek and V. Paidar, to be published (2018).

21. M.D. Nave and M.R. Barnett, Scripta Mater. 51, 881 (2004).

22. J. Koike, Y. Sato, and D. Ando, Mater. Trans. 49, 2792 (2008).

23. H.E. Kadiri, J.C. Baird, J. Kapil, A.I. Oppedal, M. Cherkaoui, and S.C. Vogel, Int. J. Plast. 44, 111 (2013).

24. J. Koike, Metall. Mater. Trans. A 36, 1689 (2005).

25. Q. Sun, X.Y. Zhang, Y. Ren, L. Tan, and J. Tu, Mater. Charact. 109, 160 (2015).

\section{Деякі аспекти вторинного двійникування в гексагональних металах}

\section{A. Ostapovets, V. Paidar}

Якщо пластична деформація не може здійснюватись шляхом дислокаційного ковзання, часто активується механічне двійникування. Ця ситуація часто виникає в гексагональних матеріалах. Поряд із звичайними границями зерен, двійникові границі, як спеціальні границі розділу, відіграють важливу роль у формуванні не тільки механічних, але й інших властивостей матеріалів. У цьому короткому повідомленні увага зосереджена лише на деяких процесах, пов'язаних з вторинним двійникуванням та умовами його виникнення. Аналізуються геометричні аспекти механізмів формування різних двійникових границь розділу у контексті вторинного двійникування.

Ключові слова: гексагональні метали, механічні властивості, двійникування.

\section{Некоторые аспекты вторичного двойникования в гексагональных металлах}

\section{A. Ostapovets, V. Paidar}

В случае, если пластическая деформация не может осуществляться путем дислокационного скольжения, часто активируется механическое двойникование. Эта ситуация часто возникает в гексагональных материалах. Наряду с обычными границами зерен, двойниковые границы, как специальные границы раздела, играют важную роль в формировании не только механических, но и других свойств материалов. В этом коротком сообщении внимание сосредоточено лишь на некоторых процессах, связанных с вторичным двойникованием и условиями его возникновения. Анализируются геометрические аспекты механизмов формирования различных двойниковых границ раздела в контексте вторичного двойникования.

Ключевые слова: гексагональные металлы, механические свойства, двойникование. 